\title{
Is Stem Cell a Curer or an Obstruction?
}

\author{
Siska Darmayanti ${ }^{1,2}$, Rina Triana ${ }^{1,2}$, Angliana Chouw ${ }^{1,3}$, Nurrani Mustika Dewi ${ }^{1,2}$ \\ ${ }^{1}$ Faculty of Pharmacy, Padjajaran University, Bandung, Indonesia \\ ${ }^{2}$ Prodia Clinical Laboratories, Jakarta Indonesia \\ ${ }^{3}$ Prodia Stem Cell, Jakarta, Indonesia
}

\begin{abstract}
Stem cell research and therapy are progressing these days dramatically. Stem cell therapy holds enormous treatment potential for many diseases which currently have no or limited therapeutic options. Unfortunately, this potential also comes with side-effects. In this review, the positive and negative effects of regulation of stem cells will be explained. Stem cells are undifferentiated cells which able to develop into many different cells of types in the body during early life and growth. There are five types of stem cells: embryonic stem cells, induced pluripotent stem cells, somatic stem cells, fetal stem cells and mesenchymal stem cells. Stem cell transplantation is one form of stem cell therapy, it comes with different techniques sourced, and those are autologous and allogeneic transplantation stem cells. In an autologous transplant, a patient's blood-forming stem cells are collected, meanwhile, in an allogeneic transplant, target cells are replaced with new stem cells obtained from a donor or donated umbilical cord blood. Its abilities to maintain the phenotype, self-renewing and differentiate itself into specialized cells, give rise to stem cell as an innovation for the treatment of various diseases. In the clinical setting, stem cells are being explored for different conditions, such as in tissue repair and regeneration and autoimmune diseases therapy. But along with its benefit, stem cell therapy also holds some harm. It is known that the treatment using stem cell for curing and rehabilitation has the risk of tumor formation.
\end{abstract}

Keywords: stem cell, therapy, transplantation, tumorigenic, mesenchymal stem cell, allogeneic

\section{Introduction}

A cell is the smallest unit of living matter and the basic functional unit of life. The human body is consists of 100 trillion cells, and each cell is assigned to a specialized function to perform. Some cells function as the brain (neurons), while others as our hearts (cardiac myocytes), our skin (fibroblasts) our pancreas (pancreatic cells), etc. All these functional cells are originated from an unspecialized cell, called stem cell. Stem cells have two unique properties: they can multiply and become other types of cells (differentiated).
Stem cells have the potential to yield new therapies, new insights into disease and a clearer understanding of tissue formation and maintenance. ${ }^{1}$ Stem cell research and therapy have now progressed dramatically with countless research studies are being published each year in scientific journals. Stem cell therapy offers the promise to treat degenerative diseases, cancer, damaged tissues repairing and an alternate source of biological material for cell restorative treatments which currently have no or limited therapeutic options. ${ }^{2,3}$ There is no doubt that stem cell therapy holds huge potential. Unfortunately, this potential also comes with

Date of submission: December 31, 2016

Last Revised: March 20, 2017

Accepted for publication: March 30, 2017

Corresponding Author:

Siska Darmayanti

Faculty of Pharmacy, Padjajaran University

Jl. Eijkman No.38, Bandung, Indonesia

E-mail: siska.darmayanti@gmail.com

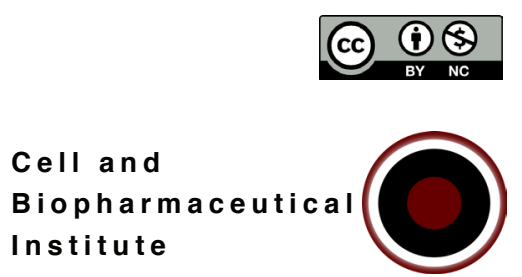


side-effects. In this review, the positive and negative effects of regulation of stem cells will be explained.

\section{Stem cells}

Stem cells are undifferentiated cells that have the remarkable potential to develop into many different cell types of the body of early life and growth. The term "stem cell" goes far to 1908 when Russian histologist Alexander Maximow developed and introduced a theory of hematopoiesis, a theory upon which our present concept of blood cells' origin and differentiation is based. After being identified the first time for the hematopoietic system, they are also likely to be present in many other tissues. The field of stem cell is rapidly developing, it has changed the care of individuals with hematologic, oncologic, dermatologic, ophthalmologic and orthopedic conditions. ${ }^{2-4}$ The thriving role of stem cells in clinical medicine is developing along at least three lines: stem cells as therapy (either to replace cell lines that have been lost or destroyed or to modify the behavior of other cells), stem cells as targets of drug therapy and stem cells to generate differentiated tissue for in vitro study of disease models for drug development. ${ }^{5}$

Stem cells are distinguished from other cell types by two important characteristics. First, they are unspecialized cells capable of renewing themselves through cell division, sometimes after long periods of inactivity. Stem cells are hypothesized to be able to divide symmetrically (in which both daughter cells are either stem cells or differentiated cells) or asymmetrically (yielding one stem cell and one more differentiated cell). ${ }^{5,6}$ Second, under certain physiologic or experimental conditions, they can be induced to become tissue- or organ-specific cells with special functions. In some organs, such as the gut and bone marrow, stem cells regularly divide to repair and replace worn out or damaged tissues. In other organs, however, such as the pancreas and the heart, stem cells only divide into special conditions. ${ }^{6,7}$

Stem cells have potency to be either totipotent, pluripotent, multipotent or unipotent. Totipotent cells can form all types of cells in the body, including embryonic and extra-embryonic tissue. Pluripotent is able to make all cells of the embryo, including germ cells and cells from any of the germ layers. Meanwhile, multipotent cells can only make cells within a given germ layer. For instance, multipotent stem cells from a mesodermal tissue like the blood hematopoietic stem cell can make all the cells in the blood, but cannot produce cells of a different germ layer such as neural cells (ectoderm) or liver cells (endoderm). A unipotent stem cell has the capacity for make a single cell type. An example is a germ cell stem cell that makes the cells that mature to become egg or sperm, but not other cell types. The potency of cells is located at the time the embryonic development of organisms. Cells that have totipotency are arising from the first few cell divisions after fertilization of the egg. Pluripotent cells were thought to be limited to cells derived from either the inner cell mass of the blastocyst or nascent germ cells in the embryo. Now we have known that pluripotent cells can arise from other cell types as well. Within 10 to 14 days after conception of humans, most stem cells are restricted to be either multipotent or unipotent. ${ }^{6,7}$

\section{Sources of stem cells}

\section{Embryonic stem cell (ESC)}

The origin of the ESCs is the embryo. They came 7-10 days after fertilization of the pre-implantation blastocyst. In the early 1960s, researchers isolated a single cell type of a teratocarcinoma, a tumor derived from a germ cell. These embryonal embryonic carcinoma cells are the stem cells of teratocarcinoma's which can be considered as the malignant counterparts of ESCs that originate from the inner cell mass of a blastocyst-stage embryo. The embryonal embryonic carcinoma cells replicate and grow in cell culture conditions.

In 1981, ESCs were first derived from mouse embryos. ${ }^{89}$ The technique was by culturing the mouse ESCs from embryos in the uterus to increase cell numbers, allowing for the derivation of ESCs from these embryos. The development is continue to isolate and grow human ESCs in cell cultures in $1998 .{ }^{10}$ The research on teratocarcinoma, embryonal embryonic carcinoma cells and ESCs which have been carried out over the past 50 years passed through several distinct phases as seen in Figure 1. ${ }^{11}$

ESCs are pluripotent cells that have the ability to differentiate between derivatives of all three germ layers (endoderm, mesoderm, and ectoderm). Pluripotent stem cells in mice have the potency to form chimeras after injection of early blastocysts. ${ }^{11,12}$ ESCs are derived from totipotent cells of the inner cell mass of the blastocyst, an early stage mammalian embryo. These cells are capable of unlimited, undifferentiated proliferation in vitro. In mouse embryo chimeras ESCs can differentiate from a range of adult tissues. Also, human ESCs have a large differentiation potential and can form cells from all embryonic germ layers. ${ }^{10,13,14}$ 


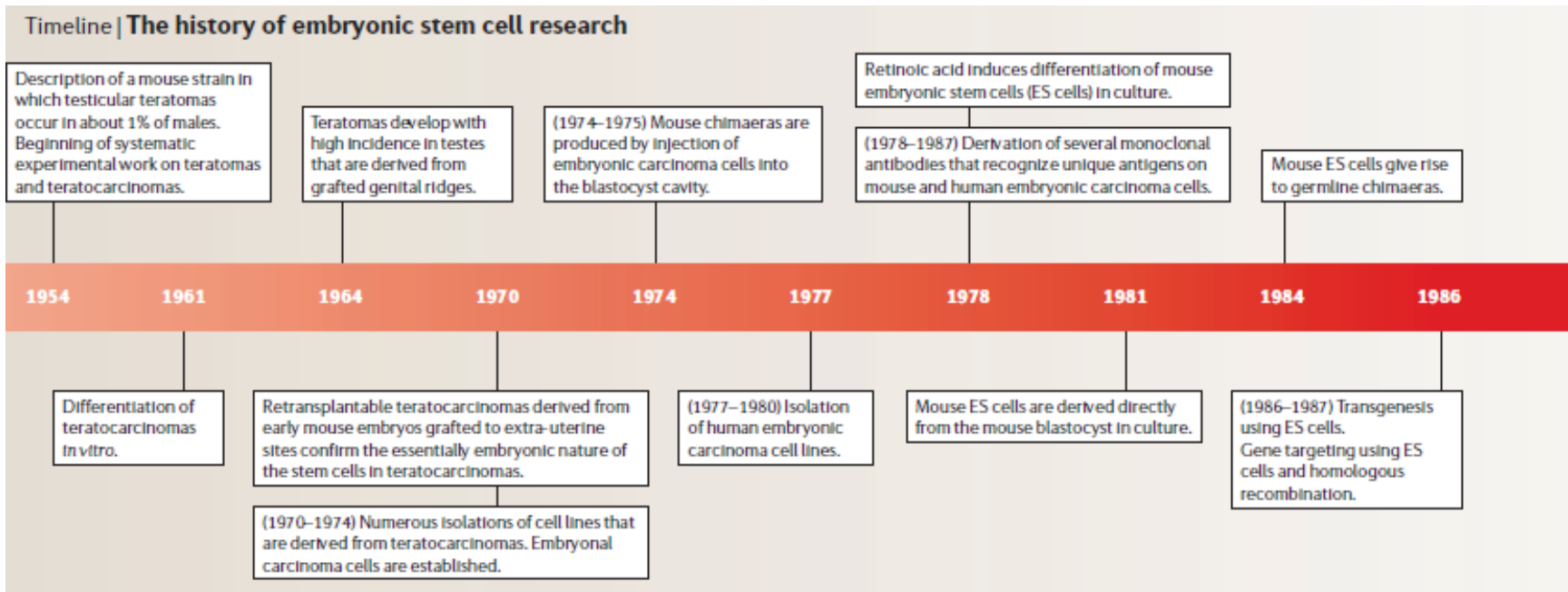

Figure 1. Timeline history of ESC research. ${ }^{11}$ (With permission from Nature Publishing Group).

\section{Induced pluripotent stem cell (iPSC)}

iPSCs are a type of pluripotent stem cells artificially derived from an adult differentiated somatic cell that is non-pluripotent. The transformation of an adult somatic cell into an iPSC was firstly achieved by inducing a "forced" expression of specific genes. At this moment, it has been demonstrated that the forced expression of a characterized set of transcription factors (Oct4, Sox2, c-Myc, Klf4, Nanog and Lin28) can reprogram human and mouse somatic cells into iPSCs. ${ }^{15-21}$ Most iPSC use fibroblasts for its generation, but iPSC can also been derived from liver, pancreas $\beta$-cells and mature B cells. ESC and iPSC are very similar despite the differences in their origins. They have very similar growth characteristics, gene expression profiles, epigenetic modifications and developmental potential. ${ }^{22-24}$ iPSCs are a revolutionary tool for generating in vitro models of human diseases and may help us to understand the molecular basis of epigenetic reprogramming. ${ }^{25}$

\section{Somatic stem cell (SSC)}

Multipotent adult stem cells or also known as SSC is found in differentiated tissues. The natural function of these cells is to maintenance and regenerate old or damaged tissue by replacing lost cells. SSC can be subdivided into different groups, depending on their morphology, cell surface markers, differentiation potential or tissue of origin. Scientific interest in somatic or adult stem cells has centered on their ability to divide or self-renew indefinitely, and (with certain limitations) differentiate to yield all the specialized cell types of the tissue from which it originated. In principle, SSC can be isolated from many tissues; however, cord blood and bone marrow are sources which are often used as a source of SSC for stem cell therapy. More lately, adipose tissue has also been used. Neural stem cells can be isolated from various regions of the adult brain and spinal cord..$^{26,27}$

\section{Fetal stem cell (FSC)}

A relatively new stem cell type belongs to the group of FSC which can be derived either from the fetus or extraembryonic structures of fetal origin. FSCs do not form teratomas. Various subtypes of FSCs have been described based on the tissues from which they are derived (i.e., amniotic fluid, umbilical cord, Wharton's jelly, amniotic membrane and placenta). The relatively easy accessibility and high proliferation rate makes FSC ideal sources for regenerative medicine..$^{28-31}$

\section{Mesenchymal stem cell (MSC)}

MSC which also referred to as mesenchymal or multipotent stromal cells was first discovered in the bone marrow in the early 1970s. First clinical trials performed with stem cells to repair the non-haematopoietic tissues do with MSC. ${ }^{32-}$

${ }^{33}$ MSCs have been subsequently found in many tissues, such as umbilical cord blood, adipose, brain, liver and lungs. ${ }^{34-40}$ They seen as promising cells for the treatment of a large variety of disorders, including cardiovascular, neurodegenerative and autoimmune diseases. ${ }^{41-42}$

\section{Autologous and allogenic stem cells}

Stem cell transplantation is a generic term covering different techniques. There are autologous and allogeneic transplantation stem cells. In an autologous transplant, patient's blood-forming stem cells are collected. Later, the 
collected stem cells are transplanted back into the patient, allowing the bone marrow to produce the new cell. In an allogeneic transplant, a patient use stems cells from a donor. The new stem cells are then infused into patient's bloodstream through an intravenous catheter, in a procedure that is similar to a blood transfusion. ${ }^{43,44}$ Others route of administration such as intramuscular, intratracheal or intravitreous might be used for stem cell transplantation.

It is accepted that stem cell transplants for many diseases should be initiated using autologous grafts, which are less risky and less complicated than allogeneic grafts. Here, we review the current benefits and risks of using to stem cells as therapy, more specifically about the allogeneic stem cells.

\section{Allogeneic therapy stem cell}

The prior chapter describes the characteristics and sources of stem cells. Meanwhile, in this section, we will focus on the roles and benefits of stem cells, which are mainly related to the treatment of several diseases. Stem cell transplantation is currently used as a technique for the treatment of chronic diseases. Allogeneic therapy has been a focus on clinical application because it is more efficient regarding in product availability and the number of the cells..$^{45}$

Allogeneic therapy is clearly a disruptive concept of biological system, where the dogma of immunologic is that any foreign tissue will cause an immunological reaction. As the cell-based therapies develop, MSC is a prototype that has sufficient ability to evade or suppress the immune system, so far can be used as allografts without immunosuppression. ${ }^{45}$ MSCs were first described by Friedenstein as "colony forming units-fibroblastic" due to their ability to generate single cell-derived colonies, and are adult stem cell showed functional properties that have opened the way for cell-based clinical therapies. ${ }^{46,47}$ MSCs exhibit immunosuppressive as healing capacities to improve angiogenesis and prevent apoptosis or fibrosis through the secretion of paracrine mediators (Figure 2). ${ }^{47,48}$

The secretion of bioactive molecules consists of immunomodulation, anti-apoptosis, angiogenesis, support of the growth and differentiation of local stem and progenitor cells, anti-scarring and chemoattraction. The immunomodulatory effects of MSCs are

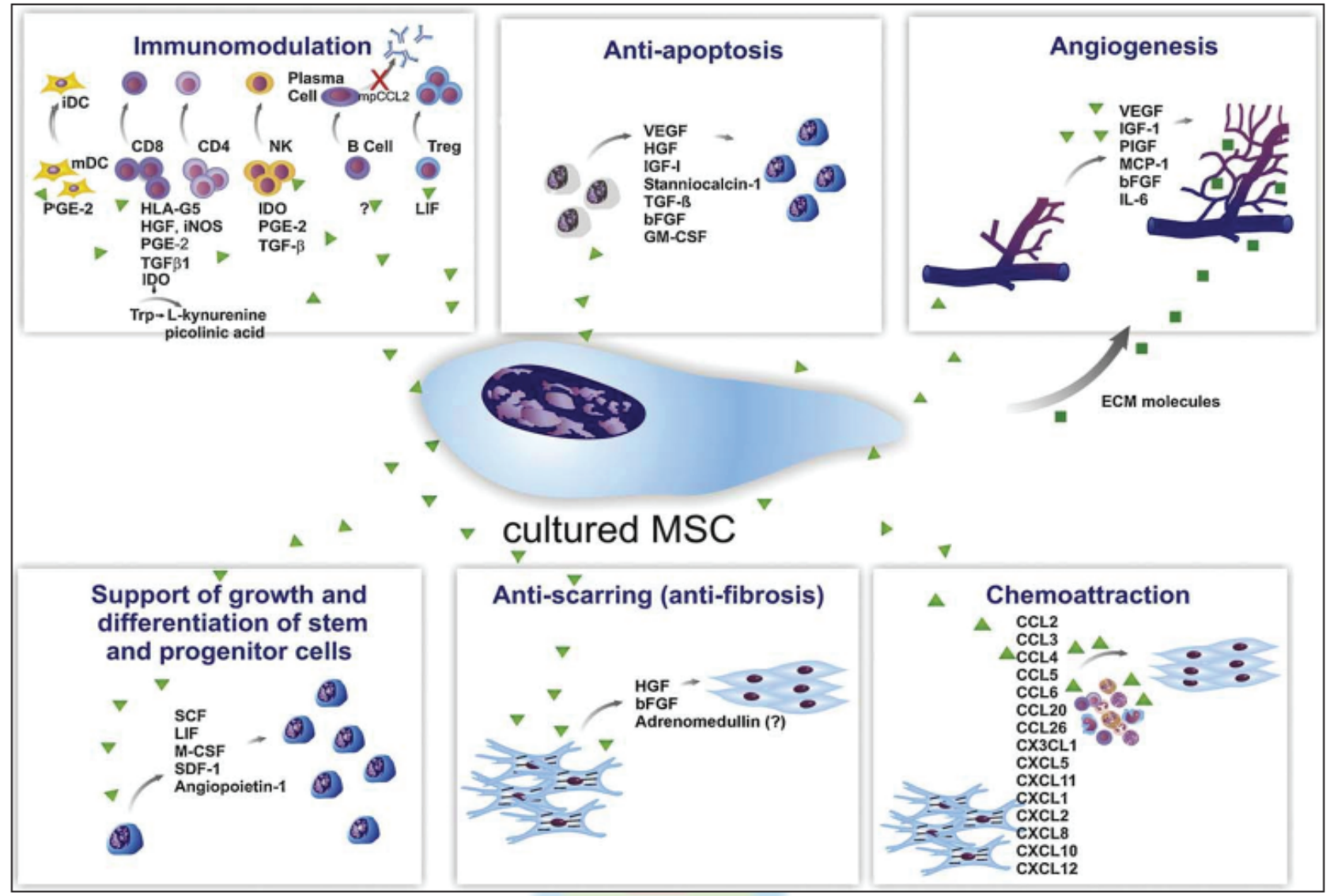

Figure 2. Paracrine effect of MSCs. ${ }^{48}$ (With permission from Springer Nature). 
inhibition of immune cell proliferation, the suppression of immunoglobulin production, the inhibition of dendritic cell maturation and the stimulation of regulatory T-cell proliferation. It also limits apoptosis and stimulates local angiogenesis through the secretion of extracellular matrix molecules. ${ }^{48}$

The essential characteristics of MSCs are their immunomodulatory and anti-inflammatory effects (Figure 3 ), and multipotent progenitor cells that have the capacity to differentiate into all lineages of mesodermal origin, e.g., cartilage, bone and adipocytes. Furthermore, MSCs can also be isolated from variety of tissues between multiple cell lineages, and possess unique immunomodulatory properties that ameliorate inflammation and immune responses. ${ }^{49,50,51}$

\section{Application of allogeneic therapy stem cell}

Allogeneic MSCs are subject to multiple quality controls compared to autologous therapy. Besides, the source of autologous use products derived from cells of the patient which are usually older and has multiple comorbidities. Cell products also depend on manufacture process and the expansion of the patient's cells are unpredictable. The process of autologous products require 4 to 6 weeks to reach sufficient numbers. In other hand, allogeneic products can be expanded on amount that may not be affordable for autologous source, undergo cryopreservation and will be available for delivery easier (Table 1). ${ }^{45,52}$

Allogeneic stem cell transplantation has the possibility of healing. It is because of the potential for immunologic graft-versus-host disease, lower rates of relapse for allograft over autograft recipients, and reduced levels and functional impairment of progenitor cells, whereas in autologous therapy relapses is a significant problem despite the fact that this treatment offer way safer side risks. . 33,54

Allogeneic MSCs has multiple mechanisms including immune privileged and immunosuppression. MSCs are considered immune privileged because of their lack of expression of major compatibility complex class (MHC) II proteins and costimulatory molecules B7 and CD40 ligand. They also exert immunosuppressive actions through inhibition of innate and adaptive immunity, e.g., inhibition of $\mathrm{T}$ cell proliferation of both $\mathrm{T}$ helper and cytotoxic $\mathrm{T}$ cells, decrease the production of the proinflammatory cytokines interferon $-\gamma$, tumor necrosis factor- $\alpha$, and interleukin (IL)214 , inhibit the activation of natural killer cells, arrest B-cell maturation and block maturation of dendritic cells. These are resulting in reduced expression of antigens and costimulatory molecules necessary to activate $\mathrm{T}$ cells and thus avoid rejection of transplantation. ${ }^{45,46,52,54}$

\section{Clinical application of allogeneic therapy stem cell}

Characteristics of stem cells are unique compared to other mammalian cells. First, they exist as unspecialized cells lacking tissue-specific features, and they maintain this phenotype until exposed to appropriate signals. Second, stem cells have the capacity for the self-renewal area. Third, under the local signal biology, it can differentiate into specialized cells with the phenotype completely different from that precursor. These gave rise to MSCs as a new and exciting innovation for the treatment of various
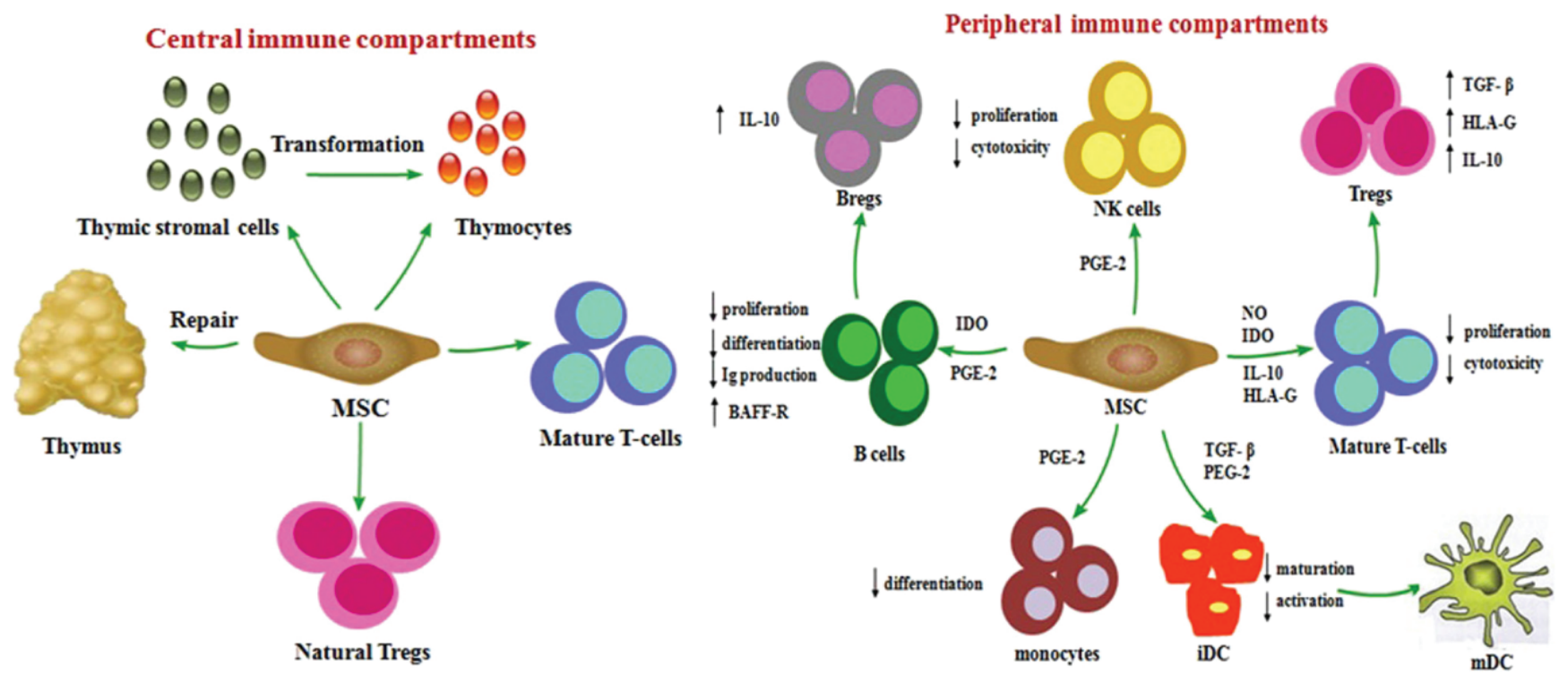

Figure 3. MSCs exert immunomodulatory effects mainly through central and peripheral immune compartments. ${ }^{50}$ (With permission from Springer Nature). 
Table 1. Comparison of autologous and allogeneic stem cell therapy. ${ }^{45,52,53,54}$

\begin{tabular}{|c|c|}
\hline Autologous Cell Therapy & Allogeneic Cell Therapy \\
\hline - Stem cells are from own body & - Stem cells are from another human being \\
\hline - No immune response & - Minimal immune response \\
\hline $\begin{array}{l}\text { - Same environment as patient - process } \\
\text { products require } 4 \text { to } 6 \text { weeks to reach } \\
\text { sufficient numbers } \\
\text { - Manufacturing failure dependent } \\
\text { - Delayed delivery }\end{array}$ & $\begin{array}{ll}\text { - } & \text { Readily available } \\
\text { - } & \text { Guaranteed dosage }\end{array}$ \\
\hline $\begin{array}{l}\text { Products derived cells of patients are } \\
\text { usually older and multiple comorbidities }\end{array}$ & - Young health donors \\
\hline - Additional invasive procedure & - No additional invasive procedure \\
\hline - High risk relapse & - Low rate relapse \\
\hline
\end{tabular}

diseases associated with inflammation, tissue damage, and subsequent regeneration and repair. ${ }^{55,56}$ In the clinical setting, stem cell are being explored for trials of various conditions, including orthopedic injuries, graft onto host disease following bone marrow transplantation, cardiovascular diseases, autoimmune diseases, and liver diseases. ${ }^{57}$

\section{Tissue repair and regeneration}

Utilization of stem cell therapy for tissue repairs are done on cartilage and cell-based therapies for cartilage defects have evolved through a few generations with various cell sources, most developing MSCs which are a multipotent endogenous of progenitors capable of differentiation to musculoskeletal tissues. ${ }^{58,59}$ Cartilage defects in the weight-bearing joint are a strenuous limitation of the patient and pose a significant burden on society and need early treatment since they have a poor intrinsic healing capacity and tend to lead to osteoarthritis, where the characteristics of osteoarthritis are characterized by progressive and irreversible degeneration of cartilage. . $8,60,61^{-}$

Application of MSCs throughout the body indicates the intrinsic role in tissue repairs and regeneration, with the ability of cells to form the mesoderm descent, able to differentiate towards osteoblasts, chondrocytes, and adipocytes. ${ }^{59}$ Intra-articular injection of MSCs in patients with osteoarthritis lead a strong improvement in the coverage and quality of cartilage, with the involvement of Transforming Growth Factor-Beta 1 (TGF- $\beta 1$ ) and InsulinLike Growth Factor 1 (IGF-1) which has a synergistic action in stimulating chondrogenesis. ${ }^{60,62}$

\section{Immune disorder therapy}

The application of MSC as regenerative medicine is now developing as an immunotherapeutic agent which capable of multilineage differentiation and paracrine factors of the MSCs-derived were able to mediate the immunomodulatory function, especially against lymphocytes $T^{63}$

The uses of MSCs in the treatment of autoimmune disease are used in multiple sclerosis, lupus, and inflammatory bowel diseases. Mechanism of MSCs in multiple sclerosis treatments is MSC suppress autoreactive Th1/Th17 proliferation and infiltration, as well as increasing accumulation of Th2 cytokines-IL-4 and IL-5and the generation of Tregs. ${ }^{63}$ The use of MSCs in reducing the lupus are capable of suppressing Th1 response.(64) In inflammatory bowel diseases, both Crohn's disease (CD) and ulcerative colitis (UC), MSC is a promising candidate for the treatment. MSC is able to decrease immune cells infiltration and TNF- $\alpha$ expression, but increases of TGF- $\beta$ levels at sites of injury. ${ }^{63,65}$

\section{Balance of stem cell through proliferation, differentiation and self-renewal}

The stem cell dynamic interaction with the microenvironment consequences of the fate of stem cell. ${ }^{66} \mathrm{It}$ is used to ensure the balance of stem cells maintains in the one organism. ${ }^{67}$ This reaction is controlled by a specific signaling pathway to cell adhesion molecules in the niche. When leaving the niche, stem cell either divides, differentiate or apoptosis. ${ }^{68}$

Stem cells niche is used to maintain stem cells identity. It consists of several types of cells. The niche, which is composed of extracellular matrix provide the 
microenvironment to maintain cell as an undifferentiated stem cell. ${ }^{69}$ The quiescence and potency of cell in the niche will be maintained to prevent stem cell losing its stemness. ${ }^{68}$ If a cells wanted to differentiate, it requires some signaling interactions with neighboring cells. ${ }^{67}$ Niche cell will provide an anchorage site, membrane-bound and secreted signal molecules to accomplish this function. ${ }^{70}$

Division of stem cell can be either symmetrical or asymmetrical. The symmetrical division is known as proliferation, it generates two daughter stem cells. ${ }^{66}$ During development periods or after an injury, stem cells will expand in numbers. ${ }^{70}$ The asymmetric division is present when stem cell differentiates. The asymmetric cell division generates a copy of stem cell itself and the second one with limited self-renewal potential. When the cell divided, the mitotic spindle is oriented at a right angle to the cells of the niche, allowing one remain in contact with the niche while the other moves away and differentiates. ${ }^{67}$ It is to maintain the balance of stem cell and differentiated cells. ${ }^{70}$

Cell cycles are the mechanism of how cell does a selfrenewal or proliferate. ${ }^{70,71}$ During proliferation, most stem cell control in the $\mathrm{S}$ phase (DNA synthase phase) rather than G1 phase. ${ }^{71}$ The length of G1 phase during differentiation of human pluripotent stem cells indicates cell-cycle regulation. The truncated G1 phase is the character of the pluripotent state. $^{72}$

Self-renewal is a process of stem cell diving into daughter stem cells that have the similar potential for the mother cell. Stem cells divide into new cells while maintaining the undifferentiated state and also preserve they multipotency state. ${ }^{70}$ The mechanism of the unique ability of stem cells to self-renew is controlled by a specific mechanism to regulate the progress of their cell cycle. ${ }^{73}$ This mechanism is controlled by stem cell niche which gives the extrinsic signal and resulting in the effect of an intrinsic genetic pathway of the cells. ${ }^{69}$ The regulation of circulating hormones, cytokines, and/or neural activity also affect the signaling in stem cell niche. ${ }^{70}$

The self-renewal program involves in the balance proto-oncogenes, gate-keeping tumor suppressors, and care-taking tumor suppressors that used for promoting and limiting self-renewal and maintain genomic integrity. Protooncogenes are used to promote cancer cell proliferation and stem cell self-renewal. The suppression of self-renewal is controlled by gate-keeping tumor suppressors, resulting in stem cell aging. The defects of this mechanism could lead to uncontrolled development and cancer. ${ }^{70}$ Many pathologies

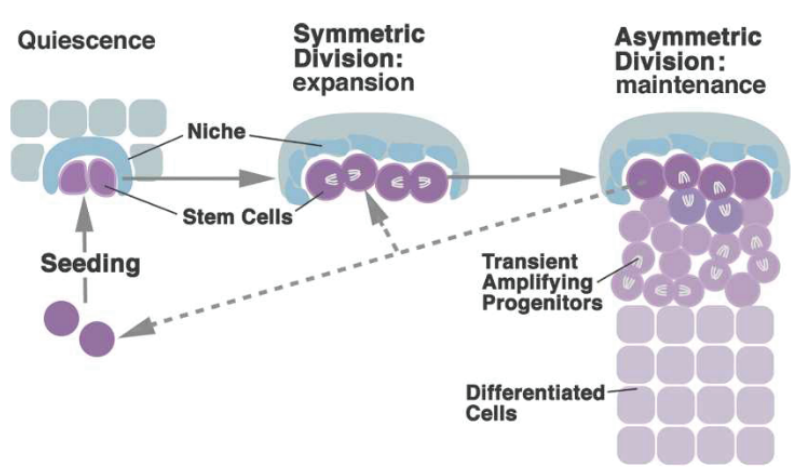

Figure 4. The stem cell dynamics: the symmetric and asymmetric cell division. ${ }^{67}$ (With permission from Cold Spring Harbor Laboratory Press).

such as tissue degeneration, aging, tumorigenesis have been associated with dysregulation of stem cell niche. Recent studies said that cancer stem cells are dependent on signals from their niche. ${ }^{66}$

As a fail-safe mechanism, gate-keeping tumor suppressors (p53, p16Ink4a, and p19Arf) prevent uncontrolled proliferation by senescence or apoptosis when activated by DNA damage, stress, or oncogenic stimuli. Care-taking tumor suppressors promote the maintenance of stem cell by maintaining the cellular integrity. ${ }^{70}$ The PI-3 kinase pathway is essential for the regulation of normal stem cell self-renewal and is frequently hyperactivated by mutations in cancer. ${ }^{74}$

Genomic integrity is important for normal function of stem cells. Accumulation genetic lesion could result in mutation of large numbers of daughter stem cells. ${ }^{70}$ DNA damaged could occur to normal DNA replication, exposure to irradiation, chemical mutagen and the product of oxidative metabolism, reactive oxygen species (ROS). This result of impairing the cellular function and the risk of cancer will increase due to the mutation..$^{70}$ If the damage is too extensive, apoptosis or senescence or cell death is one of the alternate fates of stem cells. ${ }^{67}$

Telomeres, a repetitive DNA sequences located at the end of chromosomes serves to protect the chromosome. ${ }^{75}$ When DNA replication occurs, $50-150$ base pairs of sequence at the end of the chromosome are lost in each round resulting telomeres become shorter and shorter. This became the limit of cell number division because when telomere reached the critical length, the cell will go senesces. ${ }^{70}$ The other function of the telomere is used as a protection against exonuclease and chromosomes from fusing to each other. Telomeres could extend its length because the present of telomerase 
enzyme by adding new TTAGGG repeats. ${ }^{75}$ It allows stem cells to escape the replication limits and resulting in cancer cells because the instability of cells' genetics. ${ }^{70}$

Stem cells have the capacity to protect itself from endogenous and exogenous mutagen using the repair mechanism. DNA damaged can lead to senescence, apoptosis, reduced self-renewal potential, or cancer. The result of this DNA damage will deplete the stem cell pool and reduce tissue regenerative capacity. ${ }^{70,76}$

\section{Stem cells versus tumor cells}

As ESC has its own controversy, adult stem cells are now used for regenerative medicine. This due to its ability to proliferate and differentiate into a range of progeny. However, there is a risk of tumor formation when using the stem cells for curing and rehabilitation for regenerative medicine. This led the barriers of stem cells' usage for therapy. The ability to proliferate, differentiate, and selfrenewing of stem cells and tumor cells have a common mechanism. ${ }^{77}$

The connection between stem cells and tumorigenesis is still an elusive information. In many cases, normal stem cell and cancer cell have similarity in self-renewal regulators functions. ${ }^{70}$ Tumorigenesis is known as a transformation of normal cell into a tumor cell which has abnormal proliferation. ${ }^{70,77}$ The mutations that constitutively activate oncogenes or inactivate tumor suppressors. ${ }^{70}$ This cell also can differentiate into somatic cell or adult stem cell that turns into cancer stem cell (CSC). ${ }^{77}$

MSCs are very popular with the other stem cell to be studied and used for cellular therapy. ${ }^{78}$ It has a great potential of regenerative medicine due to its ability and immunomodulatory characteristic. ${ }^{79}$ The modulation of MSC local environment for repair and regeneration is modulated by the direct cell to cell interaction or secretion of immune-related molecules. ${ }^{66}$ However, in previous studied, MSC is found to play roles in facilitating tumorigenesis and cancer. ${ }^{66,80,81}$

MSCs are multipotent and also had the ability to differentiate from three lineages: chondrocyte, adipocyte, and osteocyte. ${ }^{66,82}$ The characteristic of MSC was determined by the expression of CD44, CD73 (ecto-5'-nucleotidase), CD90 (Thy-1), CD 105 (endoglin) and HLA-ABC. MSC do not express CD34 (hematopoietic progenitor and endothelial cell marker), CD45 (pan-leukocyte marker), CD11b or CD14 (monocyte and macrophage markers), CD19 or
CD79 (B cell markers) and HLA-DR (marker of stimulated MSCs). ${ }^{66,78,82}$ In a native niche, MSC became quiescent. ${ }^{66}$ However, in recent studies said that the ESC marker such as Oct4 SSEA-4, SOX2, Nanog, and alkaline phosphatase was expressed MSC derived from bone marrow and adipose. ${ }^{78,83}$

The gene and protein expression between undifferentiated and differentiated states of MSC are reported to be different. Cytokine such as interleukine-6 (IL-6) is important to maintain MSC state because it enhances proliferation and suppresses differentiation in the chondrogenic and adipogenic state. ${ }^{66}$ The molecular regulation of MSC differentiation focused on two pathways, the Wnt canonical pathway, and the TGF- $\beta$ superfamily pathway. ${ }^{84}$ Canonical Wnt signaling pathway and extracellular matrix molecule alpha 4-laminin also found to suppress the differentiation of tri-linage. ${ }^{66}$

The immunomodulation function of MSC should be viewed as a double-edged weapon. ${ }^{85,86}$ It poses threats to diseases such as cancer. MSC secretes paracrine factor such as VEGF and SDF-1, potent chemoattractants to endothelial lineage cells, and MIP-1, -2, and MCP-5, major chemoattractants to monocytes and macrophages. MSCs constitutively secrete a host of inflammatory factors such as various interleukins, including IL-6 and GM-CSF. ${ }^{66}$ It was reported that the secretion of TGF- $\beta$ accelerated the differentiation of MSC into cancer-associated fibroblasts (CAF) that are recruited to the tumor area in SDF-1 $\alpha$ dependent manner. ${ }^{87}$ SDF-1 can trigger CAF cells via JAK2/STAT3 and MAPK/ERK signaling pathways with the subsequent organization of actin filaments and cytoskeleton. ${ }^{88}$ SDF-1 was reported to recruit endothelial progenitor cells (EPCs) which promote the angiogenesis and the tumor growth. MSC might provide tumor protection against the production of several anti-apoptotic factors such as hepatocyte growth factor (HGF), insulin-like growth factor (IGF-1), basic fibroblast growth factor (b-FGF) and granulocyte/macrophage colony stimulating factor (GMCSF). However, MSC could inhibit tumor growth by several mechanisms. The secretion of pro-inflammatory cytokines that enhance infiltration of macrophages and monocytes to the tumor area ${ }^{86}$ Such mechanism must be considerate during stem cell therapy using MSC.

\section{Summary}

As the field of stem cell is rapidly developing lately, many types of research have been done to find more information 
about the use of stem cell. Its abilities to maintain the phenotype, self-renewing and differentiate itself into specialized cells, give rise to stem cell as a new intriguing innovation for the treatment of various diseases. Stem cell therapy is said to offer considerable potential to cure diseases which currently have no cure or got limited therapeutic options. In the clinical setting, stem cells are being explored for various conditions, for example, it plays an important role in tissue repair and regeneration for cartilage defects in a weight-bearing joint. Moreover, stem cells are also known as the immunotherapeutic agent, which can be used to cure some autoimmune diseases, such as multiple sclerosis, lupus, and inflammatory bowel disease.

Like two sides of a coin, along with its benefit, stem cell therapy also holds some harm. It is known that the treatment using stem cell for curing and rehabilitation for regenerative medicine has the risk of tumor formation. Stem cells and tumor cells have a similarity mechanism in proliferating, self-renewing and differentiating. Tumorigenesis is a transformation of normal cell into a tumor cell which has abnormal proliferation, and it has been found that stem cell has roles in facilitating tumorigenesis and cancer. Meanwhile, defects of the self-renewal mechanism of stem cell could also lead to the uncontrolled development of cells and cancer.

\section{References}

1. Joseph NM, Morrison SJ. Toward an understanding of the physiological function of mammalian stem cells. Dev Cell. 2005;9(2): 173-83.

2. Herberts CA, Kwa MS, Hermsen HP. Risk factors in the development of stem cell therapy. J Transl Med. 2011;9(1):29.

3. Master Z, McLeod M, Mendez I. Benefits, risks and ethical considerations in translation of stem cell research to clinical applications in Parkinson's disease. J Med Ethics. 2007;33(3): 16973.

4. Konstantinov IE. In search of Alexander A. Maximow: the man behind the unitarian theory of hematopoiesis. PerspectBiol Med. 2000;43(2): 269-76.

5. UpToDate [Internet]. WolterKluwers. In: Scadden DT, Raaijmakers M. Overview of Stem Cells. [updated 2015; cited November 25, 2016]. Available from: http://www.uptodate.com/contents/ overview-of-stem-cells?source $=$ search result\&search $=$ stem + cell\& selectedTitle $=1 \sim 150$.

6. National Institutes of Health [Internet]. Bethesda: National Institutes of Health, U.S. Department of Health and Human Services.Stem Cell Information Home Page. [updated 2016; cite November 25, 2016]. Available from: http://stemcells.nih.gov/info/basics/1.htm.

7. The University of Rodhe Island [Internet]. Shihadeh H. History and Recent Advances of Stem Cell Biology and the Implications for Human Health. Senior Honors Projects. [updated 2015; cited
November 25, 2016]. Available from: http://digitalcommons.uri. edu/srhonorsprog/421.

8. Evans MJ, Kaufman MH. Establishment in culture of pluripotential cells from mouse embryos. Nature. 1981; 292(5819): 154-6.

9. Martin GR. Isolation of a pluripotent cell line from early mouse embryos cultured in medium conditioned by teratocarcinoma stem cells. ProcNatlAcadSci USA. 1981; 78: 7634-8.

10. Thomson JA, Itskovitz-Eldor J, Shapiro SS, Waknitz MA, Swiergiel JJ, Marshall VS, et al. Embryonic stem cell lines derived from human blastocysts. Science. 1998; 282(5391): 1145-7.

11. Solter D. From teratocarcinomas to embryonic stem cells and beyond: A history of embryonic stem cell research. Nat Rev Genet. 2006; 7(4): 319-27.

12. Lengner CJ. IPS cell technology in regenerative medicine. Ann NY Acad Sci. 2010; 1192: 38-44.

13. Bradley A, Evans M, Kaufman MH, Robertson E. Formation of germline chimaeras from embryo-derived teratocarcinoma cell lines. Nature. 1984; 309(5965): 255-6.

14. Reubinoff BE, Pera MF, Fong CY, Trounson A, Bongso A. Embryonic stem cell lines from human blastocysts: Somatic differentiation in vitro. Nat Biotechnol. 2000; 18(4): 399-404.

15. Yu J, Vodyanik MA, Smuga-Otto K, Antosiewicz-Bourget J, Frane $\mathrm{JL}$, Tian $\mathrm{S}$, et al. Induced pluripotent stem cell lines derived from human somatic cells. Science. 2007; 318(5858): 1917-20.

16. Okita K, Ichisaka T, Yamanaka S. Generation of germline-competent induced pluripotent stem cells. Nature. 2007; 448(7151): 313-7.

17. Takahashi K, Tanabe K, Ohnuki M, Narita M, Ichisaka T, Tomoda $\mathrm{K}$, et al. Induction of pluripotent stem cells from adult human fibroblasts by defined factors. Cell. 2007; 131(5): 861-72.

18. Aasen T, Raya A, Barrero MJ, Garreta E, Consiglio A, Gonzalez F, et $a l$. Efficient and rapid generation of induced pluripotent stem cells from human keratinocytes. Nat Biotechnol. 2008; 26(11): 1276-84.

19. Dimos JT, Rodolfa KT, Niakan KK, Weisenthal LM, Mitsumoto $\mathrm{H}$, Chung W, et al. Induced pluripotent stem cells generated from patients with ALS can be differentiated into motor neurons. Science. 2008; 321(5893):1218-21.

20. Hockemeyer D, Soldner F, Cook EG, GaoQ, Mitalipova M, Jaenisch R. A drug-inducible system for direct reprogramming of human somatic cells to pluripotency. Cell Stem Cell. 2008; 3(3): 346-53.

21. Takahashi K, Yamanaka S. Induction of pluripotent stem cells from mouse embryonic and adult fibroblast cultures by defined factors. Cell. 2006; 126(4): 663-76.

22. Yu J, Thomson JA. Pluripotent stem cell lines. Genes Dev. 2008; 22(15): 1987-97.

23. Saric T, Hescheler J. Stem cells and nuclear reprogramming. Minim Invasive Ther Allied Technol. 2008; 17(2): 64-78.

24. Xu N, Papagiannakopoulos T, Pan G, Thomson JA, Kosik KS. MicroRNA-145 regulates OCT4, SOX2, and KLF4 and represses pluripotency in human embryonic stem cells. Cell. 2009; 137(4): 647-58.

25. Meiliana A, Wijaya A. Progress and future challenges of human induced pluripotents stem cell in regenerative medicine. Indones Biomed J. 2011; 3(2): 76-92.

26. Pessina A, Gribaldo L. The key role of adult stem cells: therapeutic perspectives. Curr Med Res Opin. 2006; 22(11): 2287-300.

27. Koch P, Kokaia Z, Lindvall O, Brustle O. Emerging concepts in neural stem cell research: autologous repair and cell-based disease modelling. Lancet Neurol. 2009; 8(9): 819-29.

28. Pappa KI, Anagnou NP. Novel sources of fetal stem cells: where do 
they fit on the developmental continuum? Regen Med. 2009; 4(3): 423-33.

29. De Coppi P, Bartsch ,Siddiqui MM, Xu T, Santos CC, Perin L, et al. Isolation of amniotic stem cell lines with potential for therapy. Nat Biotechnol. 2007; 25(1): 100-6.

30. Prusa AR, Marton E, Rosner M, Bernaschek G, HengstschlaÝĝer M. Oct-4-expressing cells in human amniotic fluid: A new source for stem cell research?. Hum Reprod. 2003; 18(7): 1489-93.

31. Karahuseyinoglu S, Cinar O, Kilic E, Kara F, Akay GG, Demiralp D, et al. Biology of stem cells in human umbilical cord stroma: in situ and in vitro surveys. Stem Cells. 2007; 25(2): 319-31.

32. Meiliana A,Dewi NM, Wijaya A. Mesenchymal stem cells manage endogenous tissue regeneration. Indones Biomed J. 2016; 8(2): 7190.

33. Prockop DJ, Olson SD. Clinical trials with adult stem/progenitor cells for tissue repair: let's not overlook some essential precautions. Blood. 2007; 109(8): 3147-51.

34. Kang SG, Shinojima N, Hossain A, Gumin J, Yong RL, Colman H, et al. Isolation and perivascular localization of mesenchymal stem cells from mouse brain. Neurosurgery. 2010; 67(3): 711-20.

35. Najimi M, Khuu DN, Lysy PA, Jazouli N, Abarca J, Sempoux C, et al. Adult-derived human liver mesenchymal-like cells as a potential progenitor reservoir of hepatocytes? Cell Transplant. 2007; 16(7): 717- 28.

36. Lama VN, Smith L, Badri L, Flint A, Andrei AC, Murray S, et al. Evidence for tissue-resident mesenchymal stem cells in human adult lung from studies of transplanted allografts. J Clin Invest. 2007; 117(4): 989-96.

37. Wang HS, Hung SC, Peng ST, Huang CC, Wei HM, Guo YJ, et al. Mesenchymal stem cells in the Wharton's jelly of the human umbilical cord. Stem Cells. 2004; 22(7): 1330-7.

38. Zuk PA, Zhu M, Ashjian P, De Ugarte DA, Huang JI, Mizuno H, et al. Human adipose tissue is a source of multipotent stem cells. MolBiol Cell. 2002; 13(12): 4279-95.

39. Lina Y, Wijaya A. Novel sources of fetal stem cells for future regenerative medicine. Indones Biomed J. 2012; 4(1): 3-11.

40. Lina Y, Wijaya A. Adipose-derived stem cells for future regenerative system medicine. Indones Biomed J. 2012; 4(2): 59-72.

41. Pittenger MF, Mackay AM, Beck SC, Jaiswal RK, Douglas R, Mosca JD, et al.Multilineage potential of adult human mesenchymal stem cells. Science. 1999; 284(5411): 143-7.

42. Jiang Y, Jahagirdar BN, Reinhardt RL, Schwartz RE, Keene CD, Ortiz-Gonzalez XR, et al. Pluripotency of mesenchymal stem cells derived from adult marrow. Nature. 2002; 418(6893): 41-9.

43. Memorial Sloan Kettering Cancer Center [Internet]. Blood \& Marrow Stem Cell Transplantation: Transplantation at MSK[updated 2016; cited November 25, 2016]. Available from: https://www.mskcc. org/cancer-care/treatments/cancer-treatments/blood-stem-celltransplantation/approach

44. Mamidi M, Dutta S, Bhonde R, Das A, Pal R. Allogeneic and autologous mode of stem cell transplantation in regenerative medicine: Which way to go? Med Hypotheses. 2014; 83(6): 787-91.

45. Karantalis V, Schulman I, Balkan W, Hare J. Allogeneic cell therapy: a new paradigm in therapeutics. Circ Res. 2014;116(1): 12-5.

46. Colpo G, Ascoli B, Wollenhaupt-Aguiar B, Pfaffenseller B, Silva E, Cirne-Lima E,et al.Mesenchymal stem cells for the treatment of neurodegenerative and psychiatric disorders. An Acad Bras Cienc. 2015; 87(2 Suppl): 1435-49.

47. Jorgensen C, Noël D. Mesenchymal stem cells in osteoarticular diseases. Regen Med. 2011; 6(6 Suppl): 44-51.
48. Pei X, Xi J, Yan X, Yue W, Zhou J. Mesenchymal stem cells in tissue repairing and regeneration: progress and future. Burns Trauma. 2013;1(1): 13-20.

49. Eirin A, Lerman LO. Mesenchymal stem cell treatment for chronic renal failure. Stem Cell ResTher. 2014; 5(4): 83.

50. Zhao K, Liu Q. The clinical application of mesenchymal stromal cells in hematopoietic stem cell transplantation. J HematolOncol. 2016; 9(1): 46.

51. Zhao Q, Ren H, Han Z. Mesenchymal stem cells: Immunomodulatory capability and clinical potential in immune diseases. JOCIT 2016; 2(1): $3-20$

52. Van Pham P. Clinical trials for stem cell transplantation: when are they needed? Stem Cell Res Ther. 2016; 7(1): 65.

53. Kuruvilla J. The role of autologous and allogeneic stem cell transplantation in the management of indolent B-cell lymphoma. Blood.2016; 127(17): 2093-98.

54. Rigol M, Solanes N, Roura $\mathrm{S}$, Roqué $\mathrm{M}$, Novensà L, Dantas A,et al. Allogeneic adipose stem cell therapy in acute myocardial infarction. Eur J Clin Invest. 2013; 44(1): 83-92.

55. Barry F, Murphy J, O'Brien T, Mahon B. Mesenchymal stem cell transplantation for tissue repair. SeminPlast Surg. 2005; 19(3): 22939.

56. DiMarino AM, Caplan AI, Bonfield TL. Mesenchymal stem cells in tissue repair. Frontilmmunol. 2013; 4: 201.

57. Kim N, Cho SG. Clinical applications of mesenchymal stem cells. Korean J Intern Med.2016; 28(4): 387-402.

58. Vonk L, de Windt T, Slaper-Cortenbach I, Saris D. Autologous, allogeneic, induced pluripotent stem cell or a combination stem cell therapy? Where are we headed in cartilage repair and why: a concise review. Stem Cell Res Ther. 2015; 6(1): 94.

59. WylesCC, Houdek MT, Behfar A, Sierra RJ. Mesenchymal stem cell therapy for osteoarthritis: current perspectives. Stem Cells Cloning. 2016; 8: 117-24.

60. Freitag J, Bates D, Boyd R, Shah K, Barnard A, Huguenin L,et al.Mesenchymal stem cell therapy in the treatment of osteoarthritis: reparative pathways, safety and efficacy - a review. BMC Musculoskelet Disord. 2016; 17(1): 230.

61. Uth K, Trifonov D. Stem cell application for osteoarthritis in the knee joint: aminireview. World J Stem Cells. 2014; 6(5): 629-36.

62. Trounson A, McDonald C. Stem cell therapies in clinical trials: progress and challenges. Cell Stem Cell. 2015; 17(1): 11-22.

63. Wang L, Ting C, Yen M, Liu K, Sytwu H, Wu K, et al. Human mesenchymal stem cells (MSCs) for treatment towards immuneand inflammation-mediated diseases: review of current clinical trials. J Biomed Sci. 2016; 23(1): 76.

64. Gao F, Chiu S, Motan D, Zhang Z, Chen L, Ji H,et al.Mesenchymal stem cells and immunomodulation: current status and future prospects. Cell Death Dis. 2016; 7(1): e2062.

65. Kalodimou V. Regenerative medicine applications in autoimmune disorders. J Autoimmune Disord. 2015; 1(1): 8.

66. Kuhn NZ, Tuan RS. Regulation of stemness and stem cell niche of mesenchymal stem cells: Implications in tumorigenesis and metastasis. J Cell Physiol. 2010; 222(2): 268-77.

67. Martinez-Agosto JA, Mikkola HKA, Hartenstein V, Banerjee U. The hematopoietic stem cell and its niche: a comparative view. Genes Dev. 2007;21(23): 3044-60.

68. Scadden DT. The stem-cell niche as an entity of action. Nature. 2006;441(7097): 1075-9.

69. Zhang J, Li L. Stem cell niche: microenvironment and beyond. J Biol Chem. 2008;283(15): 9499-503. 
70. Shenghui H, Nakada D, Morrison SJ. Mechanisms of stem cell selfrenewal. Annu Rev Cell Dev Biol. 2009;25(1): 377-406.

71. Nat Rep Stem Cells Online [Internet]. Mullard A. Proliferation without differentiation [updated 2008; cited December 2, 2016]. Available from: http://www.nature.com/stemcells/2008/0801/080124/full/ stemcells.2008.28.html

72. Pauklin S, Vallier L. The cell-cycle state of stem cells determines cell fate propensity. Cell. 2013; 155: 135-47.

73. Tsai RYL, McKay RDG. A nucleolar mechanism controlling cell proliferation in stem cells and cancer cells. Genes Dev. 2002; 16: 2991-3003.

74. Yuan TL, Cantley LC. PI3K pathway alterations in cancer: variations on a theme. Oncogene. 2008;27(41): 5497-510.

75. Gilson E, Géli V. How telomeres are replicated. Nat Rev Mol Cell Biol. 2007 Oct; $8(10):$ 825-38

76. Rossi DJ, Bryder D, Seita J, Nussenzweig A, Hoeijmakers J, Weissman IL. Deficiencies in DNA damage repair limit the function of haematopoietic stem cells with age. Nature. 2007; 447(7145): 725-9.

77. Lambrou GI, Remboutsika E. Proliferation versus regeneration: the good, the bad and the ugly. Front Physiol. 2014; 5: 10.

78. Sandhaanam S, Pathalam G, Dorairaj S, Savariar V.Mesenchymal stem cells (MSC): identification, proliferation and differentiation. PeerJPrePrints. 2013; 1:e148v1.

79. Zhang J, Huang X, Wang H, Liu X, Zhang T, Wang Y, et al. The challenges and promises of allogeneic mesenchymal stem cells for use as a cell-based therapy. Stem Cell Res Ther. 2015; 6: 234.

80. Djouad F, Plence P, Bony C, Tropel P, Apparailly F, Sany J, et al. Immunosuppressive effect of mesenchymal stem cells favors tumor growth in allogeneic animals. Blood. 2003; 102(10): 3837-44.
81. Dittmar T, Seidel J, Zaenker KS, Niggemann B. Carcinogenesis driven by bone marrow-derived stem cells. In: Dittmar T, Zaenker KS, Schmidt A, editors. Contributions to Microbiology. Basel: KARGER; 2006. p.156-69.

82. Dominici M, Le Blanc K, Mueller I, Slaper-Cortenbach I, Marini F., Krause DS, et al. Minimal criteria for defining multipotentmesenchymal stromal cells. The International Society for Cellular Therapy position statement. Cytotherapy. 2006; 8(4): 315-7.

83. Koltsova AM, Zenin VV, Yakovleva TK, Poljanskaya GG. Characterization of a novel mesenchymal stem cell line derived from human embryonic stem cells. Cell Tissue Biol. 2016; 10(1): $1-9$

84. Williams AR, Hare JM. Mesenchymal stem cells. Circ Res. 2011; 109(8): 923-40

85. Piscaglia AC. Stem cells, a two-edged sword: risks and potentials of regenerative medicine. World J Gastroenterol. 2008; 14(27): 4273.

86. Marsafy SE, Larghero J, Bennaceur-Griscelli A, Turhan A. Mesenchymal stem cells: pivotal players in hematopoietic stem cell microenvironment. J Stem Cell Res Ther. 2014; 4: 225.

87. Ame-Thomas P, Maby-El Hajjami H, Monvoisin C, Jean R, Monnier $\mathrm{D}$, Caulet-Maugendre $\mathrm{S}$, et al. Human mesenchymal stem cells isolated from bone marrow and lymphoid organs support tumor B-cell growth: role of stromal cells in follicular lymphoma pathogenesis. Blood. 2007; 109(2): 693-702.

88. Gao H, Priebe W, Glod J, Banerjee D. Activation of signal transducers and activators of transcription 3 and focal adhesion kinase by stromal cell-derived factor 1 is required for migration of human mesenchymal stem cells in response to tumor cell-conditioned medium. Stem Cells. 2009; 27: 857-65. 